\title{
Use of phosphoranimines to reduce organic carbonate content in Li-ion battery
}

electrolytes

Eric J. Dufek ${ }^{a,{ }^{*}}$, John R. Klaehn ${ }^{\mathrm{b}}$, Joshua S. McNally ${ }^{\mathrm{b}}$, Harry W. Rollins ${ }^{\mathrm{b}}$, and David K. Jamison $^{\mathrm{a}}$

${ }^{a}$ Energy Storage and Transportation Systems Department, Idaho National Laboratory

${ }^{b}$ Biological and Chemical Processing Department, Idaho National Laboratory

P.O. Box 1625

Idaho Falls, ID 83415

\section{Abstract}

The use of phosphoranimines (PAs), a class of linear, monomeric phosphazenes, as electrolytes for Li-ion battery applications has been investigated as a route to improve safety and stability for Li-ion batteries. Of the potential PAs for use in battery applications, this work focuses on the initial synthetic preparation and analysis of $\mathrm{N}$ trimethylsilyl-P,P-bis((2-methoxyethoxy)ethoxy)-P-ethylphosphoranimine (PA-5). PA-5 has high $\mathrm{LiPF}_{6}$ solubility in excess of $2 \mathrm{M}$, high thermal stability with a melting point below $-80^{\circ} \mathrm{C}$ and high thermal stability as a neat compound to at least $250^{\circ} \mathrm{C}$. As part of electrolyte blends, the inclusion of PA-5 shifts the onset of thermal degradation by close to $40^{\circ} \mathrm{C}$ at $35 \%$ loading and by $20^{\circ} \mathrm{C}$ at a $10 \%$ loading, improves the low temperature performance of the electrolyte, and when used as a primary solvent leads to increases in the flash point (by $20^{\circ} \mathrm{C}$ ) when compared to more traditional EC:EMC blends. Cycling capabilities of full-coin cells with graphite negative electrodes and $\mathrm{Li}_{1+w}\left[\mathrm{Ni}_{0.5} \mathrm{Mn}_{0.3} \mathrm{Co}_{0.2}\right]_{1 \text { - }}$ ${ }_{w} \mathrm{O}_{2}$ positive electrodes using PA-5:EC:EMC electrolyte blends are comparable with the performance seen for traditional EC:EMC blends. Analysis of the impact of the use of 
additives such as vinylene carbonate in PA-5:EC:EMC blended electrolyte results in enhanced capacity retention and improved coulombic efficiency.

Keywords: phosphoranimine, phosphazene, battery, electrolyte, lithium ion, safety

"Corresponding author. Tel.: +1 2085262132

E-mail: eric.dufek@inl.gov (E.J. Dufek) 


\section{Introduction}

Currently, organic carbonates serve as primary solvent components in electrolytes for Li-ion batteries (LIBs). For low to medium voltage applications, carbonates are effective, yet for high voltage use and use in extreme conditions, issues arise with the overall safety and stability of carbonate-based electrolytes. As small, highly oxygenated organic compounds, carbonates have high volatility and are combustible. This is a combination which is ill-suited for applications where a high level of safety is desired, such as in electric vehicles. Additionally, carbonate electrolytes begin to degrade at temperatures as low as $50^{\circ} \mathrm{C}$ and exhibit significant reduction in conductivity if exposed to temperatures greater than $80^{\circ} \mathrm{C}$ for more than $10 \mathrm{~h}[1,2]$. Degradation inherently leads to shortened battery life and increases in cell impedance, in addition to safety issues such as increased heat generation associated with the higher impedance. Several routes have been proposed to improve the safety of liquid electrolytes for LIBs including the use of a host of different co-solvents and additives [3].

A significant number of chemical classes and types of compounds have been proposed for improving liquid electrolyte properties. These include room temperature ionic liquids, esters, nitriles, silicon-containing compounds, ethers, sulfones and sulfoxides in addition to multiple combinations of Li salts [3]. Phosphorus-containing compounds [4-16], including phosphazenes [7, 8, 13, 14, 17-19], have received significant attention due to their flame retardant nature and high thermal stability. The use of phosphazenes in battery systems has primarily focused on cyclotriphosphazenes (CTPs) as electrolyte components $[7,13,14,17]$. Similar, yet slightly higher molecular weight CTPs and linear polyphosphazenes have also been investigated as electrode 
components including binders $[20,21]$. While some promise is shown in the use of CTPs to improve the safety of LIB electrolytes, CTP inclusion in electrolytes is limited by the amount which can be loaded into the electrolyte without increasing viscosity to a point where performance declines. As an example, at a $20 \%$ (by volume) CTP loading the viscosity of electrolyte solutions nearly doubles and the observed capacity at a $\mathrm{C} / 1$ rate declines by roughly $25 \%$ of what was observed at a C/10 rate [14]. Recently, Wu et al., reported the use of phosphorimidic compounds (triethoxyphosphazen- $\mathrm{N}$ phosphoryldiethylester, PNP) which has lower molecular weight than CTPs, but which contain two phosphorus and a singular nitrogen atom [13]. The reported data indicate that the PNP compounds have reasonable cycling ability at low loading levels ( $10 \%$ by volume) when using $\mathrm{LiFePO}_{4}$ and $\mathrm{LiMn}_{2} \mathrm{O}_{4}[13]$.

The work described below continues the investigation of lower molecular weight (below $450 \mathrm{~g} \mathrm{~mol}^{-1}$ ) phosphazene compounds with an analysis of phosphoranimines (PAs). Like the PNP compounds, $\mathrm{PAs}$ have a single $\mathrm{P}=\mathrm{N}$ unit, however PAs lack the additional phosphoryl pendant and its associated lone pairs on the O. Instead, the present PAs (Figure 1) contain a silyl moiety on the $\mathrm{N}$ as a means to reduce viscosity for use at higher loading levels and to reduce the strength of the interaction between the $\mathrm{Li}$ and the different lone pairs in the vicinity of the phosphazene $\mathrm{N}$. Other silyl compounds have recently received attention as electrolytes for similar reasons $[22,23]$. Additionally, when compared to CTPs the PAs, have lower molecular weights and remain as liquids at room temperature [24, 25]. As such they provide an option as electrolyte additives which reduce impact on viscosity while still providing the advantageous safety aspects of CTPs. As a first investigation of feasibility, this work 
looks to identify areas which need to be improved upon for further expansion PAs and other small phosphazenes.

\section{Experimental}

\subsection{Chemical Synthesis}

The synthesis of PA-5 used established methods by Neilson and Wisian-Neilson [20, 22-26] as shown in Figure 1. This route provides the opportunity, through the formation of mixed silylaminophosphines, for the production of mixed silylphosphoranimines [23-26]. As shown in Figure 1, the synthesis of the silylaminophosphine involves reaction of lithium bis(trimethylsilyl)amide $\left(\mathrm{LiN}\left(\mathrm{SiMe}_{3}\right)_{2}\right)$ with alkyldichlorophosphine $\left(\mathrm{RPCl}_{2}\right)$ to give the analogous halo(silylamino)phosphine. The aminophosphine product (1) was isolated via vacuum distillation at this stage. Following isolation of the silylaminophosphine the PA compound was generated by an oxidation step using bromine [20, 24-26]. This was done using the starting aminophosphine for PA-5 $\left[\left(\mathrm{Me}_{3} \mathrm{Si}\right)_{2} \mathrm{~N} \mathrm{P}(\mathrm{Et}) \mathrm{Cl}\right]$ (Figure 1). Subsequently, the bromine(s) were displaced with an alkoxide, sodium 2-(methoxyethoxy)ethanoxide, to give the desired phosphoranimine. Following synthesis, PA-5 which was a clear low viscosity liquid at room temperature, was characterized using ${ }^{31} \mathrm{P},{ }^{1} \mathrm{H}$, and ${ }^{13} \mathrm{C}$ NMR.

2.1.1 $\left(\mathrm{CH}_{3}\right)_{3} \mathrm{SiN}=\mathrm{P}(\mathrm{Et})\left(\mathrm{OCH}_{2} \mathrm{CH}_{2} \mathrm{OCH}_{2} \mathrm{CH}_{2} \mathrm{OCH}_{3}\right)_{2}$, (PA-5) [N-Trimethylsilyl-P,P-di(2methoxyethoxyethoxy)-P-ethylphosphoranimine): [30\% overall yield, boiling point $120-$ $125^{\circ} \mathrm{C}$ at $0.07 \mathrm{~mm} \mathrm{Hg},{ }^{31} \mathrm{P}$ NMR $\delta\left(\mathrm{CDCl}_{3}\right)=(\mathrm{s}) 23.6 ;{ }^{1} \mathrm{H}$ NMR $\delta\left(\mathrm{CDCl}_{3}\right)=$ (broad doublet, $\mathrm{JPH}=10.2 \mathrm{~Hz}$ ) 3.95-4.11, (m) 3.55-3.64, (m) 3.45-3.51, (m) 3.35-3.29, (multiplet) 1.63, (doublet of triplets, $\mathrm{JPH}=24.6 \mathrm{~Hz}, \mathrm{JHH}=7.8 \mathrm{~Hz}) 1.04$, (m) 0.0 to $-0.4 ;{ }^{13} \mathrm{C} \mathrm{NMR} \delta\left(\mathrm{CDCl}_{3}\right)$ $=(\mathrm{s}) 71.9,(\mathrm{~s}) 70.7,(\mathrm{~s}) 70.4,(\mathrm{~s}) 63.3,(\mathrm{~s})$ 58.9, (d, JPC = 140.4 Hz) 21.2, (s) 6.9, (s) 3.4]. Synthetic reagents including: $\mathrm{LiN}\left(\mathrm{SiMe}_{3}\right)_{2}\left(1.0 \mathrm{M}\right.$ in hexanes; Aldrich), $\mathrm{EtPCl}_{2}$ (Strem), $\mathrm{NaH}$ 
(95\% in oil; Aldrich), and bromine (Aldrich) were used without further purification. 2(methoxyethoxy)ethanol was obtained from Aldrich and purified by vacuum distillation. Anhydrous solvents, (diethyl ether, tetrahydrofuran, toluene, and hexanes) were obtained from Aldrich and used as received. Proton, ${ }^{13} \mathrm{C}\left({ }^{1} \mathrm{H}\right)$, and ${ }^{31} \mathrm{P}\left({ }^{1} \mathrm{H}\right)$ NMR spectra were recorded on a Bruker Ascend Avance III $600 \mathrm{MHz}$ spectrometer using $\mathrm{CDCl}_{3}$ as the NMR solvent to characterize products and intermediates during the synthetic process.

\subsection{Electrolyte preparation, characterization and electrochemical evaluation}

Eight different electrolyte blends (Table 1) were prepared by mixing different ratios (by volume) of PA-5, with 3:7 ethylene carbonate (EC, Kishida), ethyl methyl carbonate (EMC, Kishida), vinylene carbonate (VC, Sigma Aldrich) and $\mathrm{LiPF}_{6}(1.2 \mathrm{M}$ for all electrochemical tests, Kishida). $\mathrm{LiPF}_{6}$ solubility in PA-5 was determined after creating a saturated solution of $\mathrm{LiPF}_{6}$ in neat PA-5 and then analyzing only the liquid portion using inductively coupled plasma-optical emission spectrometry (ICP-OES). Conductivity was determined using a TOA CM-30R conductivity meter. A Cambridge DL-4100 (falling bob) viscometer was used for viscosity measurements. For both viscosity and conductivity, ten measurements were averaged to obtain the values reported. The closed-cup flash point for different blends was measured using a Setaflash 82000-0 equipped with an electric ignition. All electrolyte preparation, as well as the measurement of both conductivity and viscosity was performed in an Ar-filled glovebox with $\mathrm{O}_{2}$ and $\mathrm{H}_{2} \mathrm{O}$ content below $0.2 \mathrm{ppm}$. Thermal analysis was obtained using a TA Instruments (NewCastle, DE) model Q200 Differential Scanning Calorimeter (DSC). For data collection, Tzero aluminum hermetic pans were loaded with 2-6 mg of 
sample and the temperature was cycled between -90 to $250{ }^{\circ} \mathrm{C}$ at a rate of $5{ }^{\circ} \mathrm{C} \min ^{-1}$, under a purge gas $\left(\mathrm{N}_{2}\right)$ with a flow rate of $50.0 \mathrm{~mL} \mathrm{~min}^{-1}$.

Electrochemical evaluation using cyclic voltammetry (CV) of the blended electrolytes was performed using $1.0 \mathrm{~cm}^{2}$ flags of $\mathrm{Ni}$ or $\mathrm{Al}$ using a PAR 263A potentiostat in a three electrode cell which contained a $\mathrm{Li}$ counter and a $\mathrm{Li}$ quasireference electrode. Voltammetry experiments were either initiated at open circuit progressing in the negative going direction to $0.02 \mathrm{~V}(\mathrm{vs} \mathrm{Li/Li+})$ at a scan rate of $5 \mathrm{mV} \mathrm{s}^{-1}$ (for $\mathrm{Ni}$ ), or progressed from open circuit to $5.0 \mathrm{~V}\left(\mathrm{vs} \mathrm{Li}^{\mathrm{Li}}{ }^{+}\right)$for the Al flags. Cycling performance was evaluated in coin cells (CR-2032) using a full cell configuration with a Conoco Philips G8 negative electrode, and a $\mathrm{Li}_{1+w}\left[\mathrm{Ni}_{5.0} \mathrm{Co}_{2} \mathrm{Mn}_{3}\right]_{1-\mathrm{w}} \mathrm{O}_{2}$ (NCM-523) positive electrode. Electrodes were formulated and prepared at Argonne National Laboratory (ANL). A Celgard 2500 separator was used for all coin cell investigations. Voltammetry and coin cell construction were also performed in an Ar-filled glovebox.

Cell testing was performed in at least duplicate for each condition. Typically variation from duplicates remained at or below $10 \%$ with the duplicates displaying the same trends for all conditions. All full-coin cells were prepared with excess capacity for the negative electrode. Cell level specific capacities are reported based on the mass of the positive electrode. Prior to initiating testing using a calibrated Maccor 4000 series battery tester, cells were allowed to equilibrate for $2 \mathrm{~h}$ after construction in an environmental chamber (ESPEC BTU 133) at $30^{\circ} \mathrm{C}$. During testing the cells were maintained at $30^{\circ} \mathrm{C}$ for the duration of testing. Cells went through an initial 10 cycle formation at a nominal $\mathrm{C} / 10$ rate followed consecutively by evaluation ( 5 cycles each) at discharge rates of $\mathrm{C} / 5, \mathrm{C} / 3$, and $\mathrm{C} / 1$. After the rate study cells underwent 20 cycles at a 
$\mathrm{C} / 5$ rate. For the initial 25 cycles a $\mathrm{C} / 10$ rate was used for charging the cells. The final 20 cycles used a C/5 rate for both charge and discharge. Between both charge and discharge cycles a $1 \mathrm{~h}$ rest occurred in all cases. $A V_{\max }$ of $4.2 \mathrm{~V}$ and a $V_{\min }$ of $3.0 \mathrm{~V}$ was used for all cycling tests.

The performance of PA-5 blends with the solid electrolyte interphase (SEI) formation additive VC (blends $\mathbf{5}$ and $\mathbf{6}$ ) was also studied in half-coin cells as it was important to distinguish the effects of the blends on the SEI formation process. For halfcell studies positive electrode and negative electrode materials were independently tested against a Li counter electrode. As with the full-coin cells, each half-coin cell underwent initial cycling at a $C / 10$ rate to study the initial formation period. The $V_{\max }$ for the positive electrode studies was set at 4.25 with a $V_{\min }$ of $3.0 \mathrm{~V}$. Negative electrode studies used a $\mathrm{V}_{\min }$ of $0.025 \mathrm{~V}$.

\section{Results and Discussion}

As a class of compounds PAs have been investigated as precursors for the formation of polymeric phosphazenes (trimethylsilyl- group at nitrogen), however, as distinct molecular components in battery electrolytes, singular $\mathrm{P}=\mathrm{N}$ PAs have not been studied. After synthesis and NMR characterization, the physical properties of pure PA-5, and PA-5 blended with a baseline electrolyte of 3:7 EC:EMC were studied. The solubility of $\mathrm{LiPF}_{6}$ in PA-5 was determined by saturating neat PA-5 and then performing ICP-OES analysis of the liquid portion. This analysis indicated that PA-5 has a high Li solubility of $15485 \pm 1 \mu \mathrm{g} \mathrm{mL}^{-1}(2.23 \mathrm{M})$ providing the ability to formulate electrolytes which have both high Li and phosphazene content. 
Figure $2 \mathrm{~A}$ shows the comparison of viscosity for different PA-5-containing blends. The data is also included in Table 1. For pure PA-5 (blend 1) the viscosity was $148 \pm 2$ $\mathrm{CP}$ (not shown in Figure 2) while blend 2 had a lower viscosity at $42.3 \pm 0.7 \mathrm{cP}$ (not shown in Figure 2). The data for the pure, salted PA-5 (blend 1) demonstrates that while the solubility of $\mathrm{LiPF}_{6}$ is high in pure PA-5, an unacceptable increase in viscosity is observed. The viscosity decrease in blend $\mathbf{2}$ is still above what would be desired for most LIB applications, however, in blends with lower PA-5 content, as more EC:EMC mixture is added to the PA-5-containing electrolytes, the viscosity significantly decreases and the conductivity increases considerably (Figure $2 \mathrm{~A}$ and $2 \mathrm{~B}$ ). Figure $2 \mathrm{~A}$ also includes viscosity values associated with blends that contain VC (blends $\mathbf{5}$ and $\mathbf{6}$ ). The inclusion of these SEl forming additives has only marginal impact on the transport properties of the electrolyte when compared to the impact of the PA-5 loading levels.

The aim of the present set of investigations was to investigate the feasibility of using PA molecules as liquid battery electrolyte components which have chemical similarity with CTPs, but which are lower molecular weight, as a means to decrease the loading levels of organic carbonates. To provide a general comparison between the present work and prior investigations, previously reported conductivity data for a CTP, FM-2 $\left(\mathrm{C}_{12} \mathrm{H}_{21} \mathrm{~F}_{9} \mathrm{~N}_{3} \mathrm{O}_{6} \mathrm{P}_{3}\right)$ which has mixed ethoxy and trifluoroethoxy pendants, blended with 1:2 EC:EMC is included in Figure 2B [14]. Both sets of data are for blend percentages based on volume. As expected the lower molecular weight, linear PA-5 molecule maintains higher conductivity as loading levels increase when compared to the larger CTP. This is highlighted by the ability to nearly double the amount of PA-5 present when compared to FM-2 while maintaining conductivity near $0.5 \mathrm{~S} \mathrm{~m}^{-1}$. 
Combined, the data from Figure 2 suggest that the inclusion of PA-5 to loading levels in excess of $30 \%$ by volume results in electrolyte blends that are still within the range of both viscosity and conductivity observed for more traditional organic carbonate electrolytes. As such from a strictly transport related perspective, the PAs may serve as a direct means to reduce organic carbonate loading in electrolytes.

A key driver for the reduction in the use of organic carbonates for LIB electrolytes is to improve the safety of the electrolytes. Specifically, the removal of organic carbonates, especially linear, low boiling point compounds such as EMC, looks to improve the overall flammability of the electrolytes. Closed-cup flashpoint (Table 1) was chosen as an early stage comparison of safety improvement. In all the blends analyzed, an improvement to higher flashpoints when compared to the baseline electrolyte was observed. These ranged from over a $5^{\circ} \mathrm{C}$ increase for blend 5 to a $20^{\circ} \mathrm{C}$ increase for blend 2. For comparison the increase for blend $\mathbf{5}$ is roughly the same as has been observed for CTP systems at a $20 \%$ loading level [14].

Comparison of PA-5-containing electrolytes and EC:EMC-based electrolytes with lower loadings of EMC (Reduced EMC(a) and (b) in Table 1) showed very similar behavior with regard to increasing electrolyte flashpoint. This suggests that the primary improvement in closed-cup flashpoint is related to the reduction in the quantity of EMC present. This is reasonable given that the closed-cup nature of the experiment leads to results which are primarily driven by the lowest boiling point solvent present and the quantity of that solvent. For the present work, the lowest boiling point solvent is EMC. Analysis of other closed-cup flashpoints in the literature (Figure 3) show similar trends where there is a close to linear correspondence in change in flashpoint as the quantity 
of EMC is reduced and the quantity of additive is increased $[7,14]$. This comparison highlights that the driving force associated with increasing flashpoint and subsequently safety is the reduction in EMC content in the electrolyte. Thus, means to reduce the loading of the volatile organic carbonate, including the use of PA-5, are key to improving safety.

Increasing flashpoint by reducing the quantity of EMC present, can, as demonstrated in Table 1, be achieved by the simple addition of EC. However, EC has a high melting point and is a solid at room temperature. To better understand if the inclusion of PA-5 provided any benefit above EC, a series of DSC investigations were performed (Figure 4). In Figure 4A the low temperature performance of the baseline electrolyte and blends 3 and $\mathbf{4}$ are shown. For this comparison, the samples were brought to $-80^{\circ} \mathrm{C}$ and allowed to equilibrate for $10 \mathrm{~min}$. Upon initiating the positive scan a series of endo- and exothermic peaks are observed for the baseline electrolyte. These can be attributed to the energy required to the melting and solvation of LiPF 6 . For the PA-5-containing electrolytes, the performance is altered significantly where no freezing is observed (at least to $-80^{\circ} \mathrm{C}$ ). Thus the addition of PA-5 allows the electrolyte to remain as a liquid phase at temperatures where traditional EC:EMC mixes would have issues with phase transformation and freezing.

Figure $4 \mathrm{~B}$ contains data plots associated with blends 1, 3, 4, the baseline electrolyte, and neat PA-5. Of interest in these plots is the behavior between 100 and $250^{\circ} \mathrm{C}$ where, as the content of PA-5 is increased, a distinct shift in thermal performance is observed. In the case of the baseline electrolyte there is an endothermic response which initiates near $100^{\circ} \mathrm{C}$ and which peaks at $138^{\circ} \mathrm{C}$. This closely mirrors DSC values 
obtained using 3:7 EC:EMC by weight with 1.2 $\mathrm{M} \mathrm{LiPF}_{6}[26]$ and is aligned well with the boiling point of EMC. When PA-5 is introduced at a $10 \%$ by volume level (blend 4 ) a similar endothermic peak shape is observed but the response is shifted to a later onset near $120^{\circ} \mathrm{C}$, and a peak value at $140^{\circ} \mathrm{C}$. Note that the heat flow for blend 4 is also less than that observed for the baseline electrolyte. At 35\% by volume PA-5 (blend 3 ), a much later onset $\left(138^{\circ} \mathrm{C}\right)$ and a more distinct sharp endotherm is observed followed by a gradual exothermic response. At more elevated temperatures the baseline shows the initiation of another endotherm near $250^{\circ} \mathrm{C}$ which is again in agreement with other reports for 3:7 EC:EMC, and aligned near the boiling point of EC [26]. For blend 4 similar behavior is observed while for blend 3 an exotherm near $230^{\circ} \mathrm{C}$ is observed.

The distinct shifts observed in the DSC response of blends 3 and 4 can be explained by the behavior of blend $\mathbf{1}$ where there is a strong exothermic response which initiates near $115^{\circ} \mathrm{C}$ and which peaks at $146^{\circ} \mathrm{C}$. This response doesn't occur for pure PA-5 which has no distinct response between -80 and $250^{\circ} \mathrm{C}$. With the inclusion of $\mathrm{LiPF}_{6}$ the exothermic response suggests a reaction between the two is occurring. This is not completely unexpected given the fact that other silyl-phosphoranimines have been found to polymerize or cyclize, in the same temperature range as observed here $[27,28]$. If formed from the degradation of PA-5, the resulting oligomeric phosphazenes would provide a means to insulate other cell materials such as graphite from further degradation providing another route to the improvement of the safety of the battery. A more in-depth understanding of the thermal induced chemical degradation is underway.

PA compounds have typically been used as precursors for the formation of larger, polymeric phosphazene structures [27]. To assess the electrochemical stability 
of PA-5 containing electrolytes, voltammetry experiments were performed on blends 1 and 3 using a Ni flag electrode for reductive investigations and an Al flag to understand the oxidative stability of PA-5 (Figure 5). Blend 3 was chosen as it has the highest PA-5 content while still falling within the generally acceptable range for electrolyte viscosity and conductivity while blend 1 provides information on just PA-5. In Figure 5A it is seen that relatively high cathodic currents are observed on the initial sweep for blend $\mathbf{3}$ from open circuit on the $\mathrm{Ni}$ electrode with the reductive processes initiating near $1.7 \mathrm{~V}$. A secondary, more clearly defined peak is observed near $1.2 \mathrm{~V}$. These initial reductive processes correspond well with previous reports of EC-containing electrolytes on noble, $\mathrm{Cu}$ and $\mathrm{Ni}$ electrodes [29-31]. Upon change in sweep polarity there is no appreciable anodic current density (J) observed. In the second sweep, there is a significant reduction in observed cathodic $j$ with the bulk of the $j$ observed at voltages below $0.75 \mathrm{~V}$. The $j$ continues to decrease over the remainder of the first 5 cycles suggesting that there is at least a semi-stable surface interphase formed. For blend 1 the reductive window is shifted more negative, but the overall peak $j$ values are greater and less passivating behavior is also observed for blend $\mathbf{1}$.

Evaluation of the oxidative stability of blend $\mathbf{1}$ was performed using an $\mathrm{Al}$ electrode (Figure 5B). During the initial positive going sweep, the maximum observed $j$ on an $\mathrm{Al}$ electrode is $8 \mu \mathrm{A} \mathrm{cm}{ }^{-2}$. For comparison the current density observed for 1:4 EC:EMC with 1.2 $\mathrm{M} \mathrm{LiPF}_{6}$ is $10 \mu \mathrm{A} \mathrm{cm}^{-2}$ with an initiation of $\mathrm{Al}$ passivation occurring near $3.4 \mathrm{~V}$ (at a current density of $1 \mu \mathrm{A} \mathrm{cm}^{-2}$ ) as opposed to $3.78 \mathrm{~V}$ for blend 1 [31]. Following three cycles, the oxidative current is reduced such that the positive end of the electrochemical window (defined here as current densities below $1 \mu \mathrm{A} \mathrm{cm}{ }^{-2}$ ) increases 
to greater than $4.9 \mathrm{~V}$, indicating the PA electrolytes effectively passivates Al. Figure $5 \mathrm{C}$ includes the first sweep from open circuit for both the reductive and oxidative direction to highlight the differences in $j$ observed for both directions.

While the electrochemical evaluation of electrolytes using materials such as $\mathrm{Ni}$ and Al which are not active to alloying or insertion reactions, provides a good starting point in evaluating electrolytes it does not provide information on the interaction between the electrolytes and active electrode materials. As such, multiple sets of cells using G8 graphite negative electrodes and NCM-523 positive electrodes were prepared to test the performance of PA-5-containing electrolytes. Figure $6 \mathrm{~A}$ shows the first cycle charge and discharge curves for the baseline, blend 3 and blend 4 electrolytes. The results of these studies which included an initial formation period, a brief rate study and more extended cycling at a nominal $\mathrm{C} / 5$ rate are shown in Figure 6 . As can be seen in the figure, the PA-5-containing electrolytes can readily cycle, though the initial performance of the cells is below that observed for the baseline electrolyte. This lower performance is present for both blends 3 and $\mathbf{4}$, though it is noted that the lower PA-5 content blend $\mathbf{4}$ displays roughly the same capacity decrease over the entire cycling period with the exception of the initial formation cycling.

The most profound impact that the inclusion of PA-5 has on the overall performance is on cycling rate (Figure 6B). This is especially true for blend $\mathbf{3}$. The low rate capability is of interest as the viscosity of the PA-5 solutions is below CTPcontaining electrolytes which have better rate performance. As an example an electrolyte containing $20 \%$ of the CTP FM- 2 with the remainder of the electrolyte being 1:2 EC:EMC has a viscosity of roughly $6.7 \mathrm{cP}$ and exhibits a roughly $20 \%$ reduction in 
discharge capacity at a $\mathrm{C} / 1$ rate against discharge capacity at $\mathrm{C} / 10$ rate [14]. For comparison, blend 3 has a viscosity of $6.5 \mathrm{cP}$ yet has an $83 \%$ reduction in discharge capacity at a $\mathrm{C} / 1$ rate when compared to a $\mathrm{C} / 10$ rate. This significant difference between the CTP FM-2 and the monomeric PA-5 is likely attributed to properties not associated with transport in the liquid phase, or is due to high Li-binding affinity of the PA-5 molecule, or in the ability of Li ions to be transferred through the SEI formed when PA-5 is a major constituent of the electrolyte.

In comparing the charge capacity in Figure 6A there are only marginal changes between the baseline and two PA-5-containing electrolytes. However, the discharge capacities vary considerably. An evaluation of the coulombic efficiencies (CE) over the first 15 cycles ( 10 at a $\mathrm{C} / 10$ and then 5 at a $\mathrm{C} / 5$ ) was performed to better gauge the inefficiency of inclusion of the PA molecule on SEI formation (Figure 6C). When the CE for the baseline electrolyte is compared to both blends $\mathbf{3}$ and $\mathbf{4}$ it becomes evident that there are distinct differences. First, for the first ten cycles the CE for the baseline approaches $100 \%$ (except for cycle 1). In case of blends 3 and 4 the CE increases between the first two cycles, but then undergoes a decrease before again increasing. Additionally, the CE for the higher PA-5 content blend $\mathbf{3}$ is approximately $10 \%$ lower than blend $\mathbf{4}$ during early cycling. The difference between the CE in the full cell, and the voltammetry data from Figure 5 suggest that the PA- 5 may undergo different processes associated with SEI formation for the active materials vs the $\mathrm{Ni}$ flag used for $\mathrm{CV}$ analysis.

To explore the possibility of improving CE and rate capability new blends were investigated which contained the known SEl forming additive VC. These tests used 10\% 
VC (Figure 7) by volume and either 9 or $31.5 \%$ PA-5 by volume (Table 1). The inclusion of the SEI forming additive resulted in only marginal changes in the rate capabilities of the PA-5-containing electrolytes. However, the use of VC in addition to PA-5 improved the capacity retention and improved the CE over the first 15 cycles. To more effectively compare the systems with and without the SEI forming additive the capacity retention over the entire 45 cycle regime were compared (Figure 8). For the low PA-5 content blends both conditions perform relatively well with respect to retained capacity. Indeed, blend 6 slightly outperforms blend $\mathbf{4}$ and has almost identical performance to the baseline condition. Even blend $\mathbf{4}$ which contains no VC exhibits only a modest decrease in capacity when compared to the baseline. When comparing the high PA- 5 content blends the same general trend holds with blend $\mathbf{5}$ which contains VC outperforming blend 3 with respect to retained capacity. However, at the higher PA-5 content the rate performance with VC present actually is worse than blend $\mathbf{5}$.

To obtain a better grasp on the dynamics of the improved CE and capacity retention with VC and to better understand the initial cell cycling, differential capacitance plots, $d Q \mathrm{dV}^{-1}$ for the first cycle were constructed for the baseline condition and blends 3 and 5 (Figure 9). The plots highlight two distinct differences which occur during the initial cycling and SEI formation steps. First, the inclusion of higher quantities of just PA5 in blend 3 results in a shift to slightly lower onset potentials for SEI formation as evidenced by the shift of onset between the baseline condition and blend $\mathbf{3}$ from 2.95 to $2.85 \mathrm{~V}$. The inclusion of VC in blend $\mathbf{5}$ results in an even earlier onset potential for SEI formation in the full cell. To more clearly discern if the impacts observed in Figure 9A were primarily associated with the positive or the negative electrode, half-coin cell 
experiments using the high PA-5 content blends $\mathbf{3}$ and $\mathbf{5}$ were performed with the negative electrode (G8 graphite) and for the positive electrode (NCM-523). The results of this set of experiments are shown in Figures $9 \mathrm{~B}$ and $\mathrm{C}$. For the negative electrode the initial $\mathrm{i}-\mathrm{V}$ curve very closely mimics what is seen in the $d Q \mathrm{dV}^{-1}$ plots in Figure $9 \mathrm{~A}$ where the inclusion of VC shifts the onset of SEI formation to lower voltages resulting in a discernable shoulder for blend $\mathbf{5}$ which initiates near $1.2 \mathrm{~V}$. For the positive electrode data there are only marginal differences in the specific capacity for the two electrolyte systems over the first 10 cycles though there is some fade when VC is not present and the VC-containing blend $\mathbf{5}$ maintains higher CE for all 10 cycles. This varies considerably from the data shown in Figure 5 and 6 where blend 5 has a specific capacity in excess of $10 \mathrm{mAh} \mathrm{g}^{-1}$ greater than blend 3 and where blend $\mathbf{3}$ never achieves a CE greater than 0.9 during the first 5 cycles.

Taken together the data in Figures 8 and 9 suggest that the majority of the improvement observed by the inclusion of VC in the electrolyte blend occurs on the negative electrode side of the full cell. However, close examination of the CE for the data in Figure 9B does suggest that there may also be some improvement on the positive electrode side of the cell as the CE for the fifth cycle is roughly .03 greater for blend $\mathbf{5}$ than it is for blend $\mathbf{3}$. This is at least partially expected as VC has been previously been shown to improve performance for both the positive and negative electrode sides of the cell [32-34].

The combined data related to the physical properties of the PA-5-containing electrolytes and the electrochemical performance of the electrolytes suggests that they could serve as a starting point for the investigation of a new class of low molecular 
weight phosphazenes for improving the safety of Li-ion battery technologies. The ability to achieve loading levels as high as $35 \%$ by volume while maintaining viscosities below $8 \mathrm{cP}$, the improved flash point of the electrolytes, and the stability of PA-5 to $4.25 \mathrm{~V}$ are promising for these monomeric phosphazenes. Equally as promising is the fact that neat PA-5 displays good high and low temperature stability which exceeds that of linear carbonates. As such PAs, as a class of lower molecular weight phosphazenes, may serve as a route to significantly reduce the organic carbonate content in electrolytes to extents that were not possible using CTPs. However, there is still significant improvement which needs to occur for successful implementation. First the stability of the PA compounds at low voltages needs to improve. Stability at higher voltages and against other electrode materials such as Si also needs to be evaluated. Currently work to improve and understand performance for these areas is underway.

\section{Conclusions}

The initial characterization of PAs for use as components of battery electrolytes is reported. As a monomeric phosphazene PA-5 offers the ability to maintain significantly lower electrolyte viscosity when compared to other electrolyte additives and co-solvent systems. The physical properties of the PA-5-containing electrolytes are highlighted by a viscosity below $7 \mathrm{cP}$ and conductivities above $0.5 \mathrm{~S} \mathrm{~m}^{-1}$ for blend 3 and high thermal stability for the PA-5 molecule at both high and low temperatures. In electrolyte blends the addition of PA-5 reduces the freezing point of the electrolyte and shifts the onset of high temperature thermal degradation by $20-40^{\circ} \mathrm{C}$ at $10-35 \%$ loading.

The inclusion of the SEI forming additive VC improves the performance of the electrolytes having significant increases in capacity retention and CE. For systems with 
lower PA-5 content the capacity retention over the initial 45 cycles is on par with the performance of baseline electrolyte with the VC-containing electrolyte performing better than the PA-5 blends which did not contain the additive. It was found that the bulk of the improvement observed for the VC-containing electrolytes occurs on the negative electrode side of the cell, though there is some improvement observed for positive electrode performance.

\section{Acknowledgements}

Work supported through the INL Laboratory Directed Research and Development (LDRD) Program, Project 15-125, under DOE Idaho Operations Office (Contract No. DE-AC07-05ID14517). The author's would like to thank Fred Stewart at INL for discussion during the experimental investigation, Bryant Polzin at ANL, and Peter Faguy in the Vehicle Technologies Office of DOE-EERE for access to electrode laminate samples. This manuscript has been authored by Battelle Energy Alliance, LLC under Contract No. DE-AC07-05ID14517 with the U.S. Department of Energy. The United States Government retains and the publisher, by accepting the article for publication, acknowledges that the United States Government retains a nonexclusive, paid-up, irrevocable, world-wide license to publish or reproduce the published form of this manuscript, or allow others to do so, for United States Government purposes. 


\section{References}

[1] B. Ravdel, K. M. Abraham, R. Gitzendanner, J. DiCarlo, B. Lucht, and C. Campion, Thermal stability of lithium-ion battery electrolytes, J Power Sources 119 (2003) 805-810.

[2] C. Arbizzani, G. Gabrielli, and M. Mastragostino, Thermal stability and flammability of electrolytes for lithium-ion batteries, J Power Sources 196 (2011) 4801-4805.

[3] K. Xu, Electrolytes and Interphases in Li-lon Batteries and Beyond, Chem Rev 114 (2014) 11503-11618.

[4] S. Dalavi, M. Xu, B. Ravdel, L. Zhou, and B. L. Lucht, Nonflammable Electrolytes for Lithium-Ion Batteries Containing Dimethyl Methylphosphonate, J Electrochem Soc 158 (2010) A1113-A1120.

[5] R. P. Dunn, J. Kafle, F. C. Krause, C. Hwang, B. V. Ratnakumar, M. C. Smart, et al., Electrochemical Analysis of Li-Ion Cells Containing Triphenyl Phosphate, J Electrochem Soc 159 (2012) A2100-A2108.

[6] M. Xu, D. Lu, A. Garsuch, and B. L. Lucht, Improved Performance of LiNi0.5Mn1.504 Cathodes with Electrolytes Containing Dimethylmethylphosphonate (DMMP), J Electrochem Soc 159 (2012) A2130A2134.

[7] M. K. Harrup, H. W. Rollins, D. K. Jamison, E. J. Dufek, K. L. Gering, and T. A. Luther, Unsaturated phosphazenes as co-solvents for lithium-ion battery electrolytes, J Power Sources 278 (2015) 794-801. 
[8] A. Seyoung, K. Hyun-Soo, Y. Sunhye, D. Jung Yun, K. Byung Hwa, and K. Ketack, Thermal stability and performance studies of LiCo $1 / 3 \mathrm{Ni} 1 / 3 \mathrm{Mn} 1 / 3 \mathrm{O} 2$ with phosphazene additives for Li-ion batteries, J Electroceram 23 (2009) 289294.

[9] A. von Cresce and K. Xu, Electrolyte Additive in Support of 5 V Li lon Chemistry, J Electrochem Soc 158 (2011) A337-A342.

[10] P. Ping, Q. S. Wang, J. H. Sun, X. Xia, and J. R. Dahn, Studies of the Effect of Triphenyl Phosphate on Positive Electrode Symmetric Li-Ion Cells, J Electrochem Soc 159 (2012) A1467-A1473.

[11] X. Xia, P. Ping, and J. R. Dahn, Studies of the Effect of Triphenyl Phosphate on the Negative Electrode of Li-Ion Cells, J Electrochem Soc 159 (2012) A1460A1466.

[12] R. P. Dunn, C. C. Nguyen, and B. L. Lucht, Flame-retardant co-solvent incorporation into lithium-ion coin cells with Si-nanoparticle anodes, J Appl Electrochem 45 (2015) 873-880.

[13] B. B. Wu, F. Pei, Y. Wu, R. J. Mao, X. P. Ai, H. X. Yang, et al., An electrochemically compatible and flame-retardant electrolyte additive for safe lithium ion batteries, J Power Sources 227 (2013) 106-110.

[14] H. W. Rollins, M. K. Harrup, E. J. Dufek, D. K. Jamison, S. V. Sazhin, K. L. Gering, et al., Fluorinated phosphazene co-solvents for improved thermal and safety performance in lithium-ion battery electrolytes, J Power Sources 263 (2014) 66-74. 
[15] Z. Q. Zeng, X. Y. Jiang, B. B. Wu, L. F. Xiao, X. P. Ai, H. X. Yang, et al., Bis(2,2,2-trifluoroethyl) methylphosphonate: An Novel Flame-retardant Additive for Safe Lithium-ion Battery, Electrochim Acta 129 (2014) 300-304.

[16] X. M. Zhu, X. Y. Jiang, X. P. Ai, H. X. Yang, and Y. L. Cao, Bis(2,2,2Trifluoroethyl) Ethylphosphonate as Novel High-efficient Flame Retardant Additive for Safer Lithium-ion Battery, Electrochim Acta 165 (2015) 67-71.

[17] T. Tsujikawa, K. Yabuta, T. Matsushita, T. Matsushima, K. Hayashi, and M. Arakawa, Characteristics of lithium-ion battery with non-flammable electrolyte, $\mathrm{J}$ Power Sources 189 (2009) 429-434.

[18] C. W. Lee, R. Venkatachalapathy, and J. Prakash, A novel flame-retardant additive for lithium batteries, Electrochem Solid St 3 (2000) 63-65.

[19] K. Xu, M. S. Ding, S. S. Zhang, J. L. Allen, and T. R. Jow, An attempt to formulate nonflammable lithium ion electrolytes with alkyl phosphates and phosphazenes, J Electrochem Soc 149 (2002) A622-A626.

[20] E. J. Dufek, M. L. Stone, D. K. Jamison, F. F. Stewart, K. L. Gering, L. M. Petkovic, et al., Hybrid phosphazene anodes for energy storage applications, J Power Sources 267 (2014) 347-355.

[21] S. T. Fei and H. R. Allcock, Methoxyethoxyethoxyphosphazenes as ionic conductive fire retardant additives for lithium battery systems, J Power Sources 195 (2010) 2082-2088.

[22] D. R. Gallus, R. Wagner, S. Wiemers-Meyer, M. Winter, and I. Cekic-Laskovic, New insights into the structure-property relationship of high-voltage electrolyte 
components for lithium-ion batteries using the pK(a) value, Electrochim Acta 184 (2010) 410-416.

[23] B. Pohl, M. Grunebaum, M. Drews, S. Passerini, M. Winter, and H. D. Wiemhofer, Nitrile functionalized silyl ether with dissolved LiTFSI as new electrolyte solvent for lithium-ion batteries, Electrochim Acta 180 (2015) 795-800.

[24] J. R. Klaehn and R. H. Neilson, Synthesis and characterization of mixedsubstituent N-silylphosphoranimines, Inorg Chem 41 (2002) 5859-5865.

[25] J. R. Klaehn, T. A. Luther, M. K. Harrup, and F. F. Stewart, Synthesis and characterization of mixed-substituent $\quad$ P-n-propyl-Ntrimethylsilylphosphoranimines, Phosphorus Sulfur 178 (2003) 1587-1603.

[26] Z. Chen, Y. Qin, Y. Ren, W. Lu, C. Orendorff, E. P. Roth, et al., Multi-scale study of thermal stability of lithiated graphite, Energy Environ Sci, 4 (2011) 4023-4030.

[27] R. H. Neilson and P. Wisian-Neilson, POLY(ALKYL/ARYLPHOSPHAZENES) AND THEIR PRECURSORS, Chem Rev 88 (1988) 541-562.

[28] V. Blackstone, A. J. Lough, M. Murray, and I. Manners, Probing the Mechanism of the PCl5-Initiated Living Cationic Polymerization of the Phosphoranimine Cl3P = NSiMe3 using Model Compound Chemistry, J. Am. Chem. Soc. 131 (2009) 3658-3667.

[29] D. Aurbach, M. Moshkovich, Y. Cohen, and A. Schechter, The study of surface film formation on noble-metal electrodes in alkyl carbonates/Li salt solutions, using simultaneous in situ AFM, EQCM, FTIR, and EIS, Langmuir 15 (1999) 2947-2960. 
[30] E. J. Dufek, Evaluation of the SEI Using a Multilayer Spectroscopic Ellipsometry Model, ECS Electrochm Lett 3 (2014) A108-A111.

[31] S. V. Sazhin, K. L. Gering, M. K. Harrup, and H. W. Rollins, Highly Quantitative Electrochemical Characterization of Non-Aqueous Electrolytes and Solid Electrolyte Interphases, J Electrochem Soc 161 (2014) A393-A402.

[32] L. Madec, R. Petibon, K. Tasaki, J. Xia, J. P. Sun, I. G. Hill, et al., Mechanism of action of ethylene sulfite and vinylene carbonate electrolyte additives in LiNi1/3Mn1/3Co1/3O2/graphite pouch cells: electrochemical, GC-MS and XPS analysis, Phys Chem Chem Phys 17 (2015) 27062-27076.

[33] D. Aurbach, K. Gamolsky, B. Markovsky, Y. Gofer, M. Schmidt, and U. Heider, On the use of vinylene carbonate (VC) electrolyte solutions for Li-ion as an additive to batteries, Electrochim Acta 47 (2002) 1423-1439.

[34] H. Ota, K. Shima, M. Ue, and J. Yamaki, Effect of vinylene carbonate as additive to electrolyte for lithium metal anode, Electrochim Acta 49 (2004) 565-572. 


\section{Figure Captions}

Figure 1: Synthetic scheme for the production of PA-5 using previously reported techniques.

Table 1: Electrolyte blends and determined flashpoints, conductivities and viscosities for assorted blends. All blends are at 1.2 $\mathrm{M} \mathrm{LiPF}_{6}$

Figure 2: Viscosity (2A) and conductivity (2B) for various PA-5 containing electrolytes. Data recorded at $20^{\circ} \mathrm{C}$. Data for CTP from Ref. 14. The error bars for both $2 \mathrm{~A}$ and $2 \mathrm{~B}$ are of the same size or smaller than the denoted points for each condition. Lines drawn to aid the reader.

Figure 3: Analysis of the closed-cup flashpoints for electrolytes containing CTPs (from Refs. 7 and 14), differing levels of EMC and PA-5.

Figure 4: DSC of baseline and various PA-5-containing electrolytes. Exothermic is positive in the plot. The data is offset to aid in discerning the plots. Total Heat flow from $100-200^{\circ} \mathrm{C}$ in $\mathrm{W} \mathrm{g}^{-1}$ is included in the legend.

Figure 5: Cyclic voltammetry looking at the reductive stability of blends 1 and $3(A)$ and oxidative stability of blend 1 (B). Scan rate $5 \mathrm{mV} \mathrm{s}^{-1}, \mathrm{~V}_{\min } 0.02 \mathrm{~V}$ vs $\mathrm{Li}^{\prime} / \mathrm{Li}^{+}$(reductive sweep) and $V_{\max } 5.0 \mathrm{~V}$ (oxidative sweep). Data recorded using a $1 \mathrm{~cm}^{2}$ flags electrode in a three electrode cell. C) The first sweep for both the reductive and oxidative directions showing the full electrochemical response for $\mathrm{Ni}$ and $\mathrm{Al}$ electrodes.

Figure 6: A) Charge-discharge profile for the baseline electrolyte and blends 3 and 4 B) Discharge capacities for baseline and blends 3 and 4 C) CE for the first 15 cycles for baseline and blend 3 and 4 . 
Figure 7: A) Discharge capacities for baseline with 10\% VC, blend 5 and 6 B) CE for the first 15 cycles for baseline with $10 \%$ VC, and for blend 5 and 6 .

Figure 8: Capacity retention for the different PA-5 containing blend formulations and the baseline conditions.

Figure 9: A) $d Q d V^{-1}$ analysis for the initial stages of SEl formation during the first cycle for blends 3, 5 and the baseline electrolyte B) Initial charge i-V curve for half cells using a graphite negative electrode for blends 3, and 5 C) Discharge capacities and CE for half-cells using a NCM-523 positive electrode for blends $\mathbf{3}$ and $\mathbf{5}$. 
Figure 1:
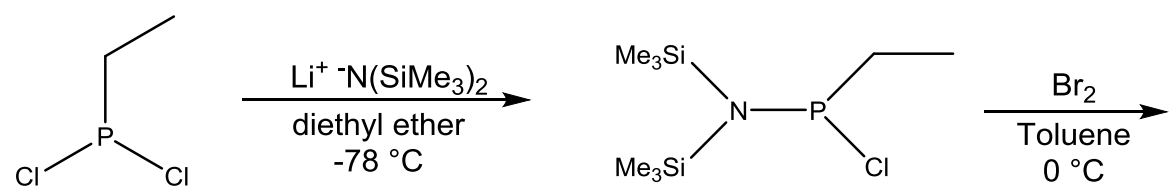

(1)
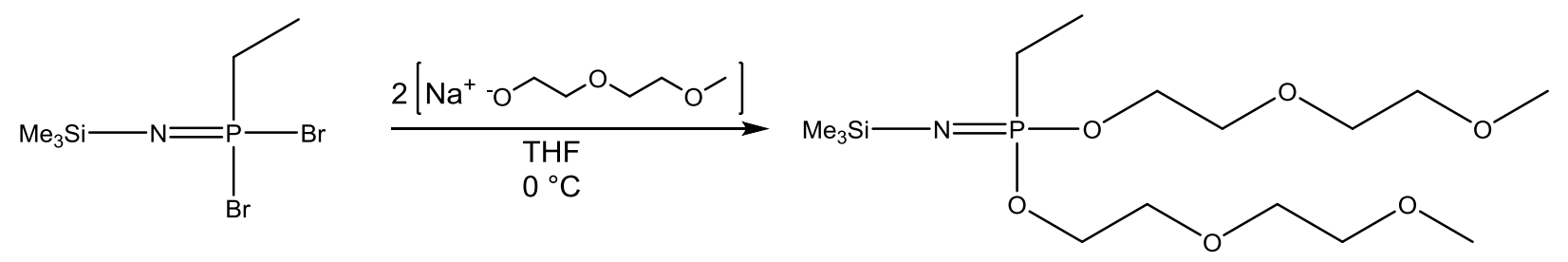

PA-5 
Table 1

\begin{tabular}{|c|c|c|c|c|c|c|c|}
\hline $\begin{array}{l}\text { Blend } \\
\text { Number }\end{array}$ & $\begin{array}{l}\text { Volume } \\
\% \text { PA-5 }\end{array}$ & $\underset{E C}{\text { Volume }} \%$ & $\begin{array}{c}\text { Volume } \% \\
\text { EMC }\end{array}$ & $\begin{array}{c}\text { Volume } \\
\% \text { VC }\end{array}$ & $\begin{array}{c}\text { Closed- } \\
\text { Cup } \\
\text { Flashpoint } \\
\left(^{\circ} \mathrm{C}\right)\end{array}$ & $\begin{array}{c}\text { Viscosity } \\
, \eta(c P \text {, at } \\
\left.20^{\circ} \mathrm{C}\right)_{-}\end{array}$ & $\begin{array}{l}\text { Conductivity } \\
\left(\mathrm{S} \mathrm{m}^{-1} \text {, at }\right. \\
\left.\left.20^{\circ} \mathrm{C}\right)\right)\end{array}$ \\
\hline Baseline & 0 & 30 & 70 & 0 & 29.0 & $4.20 \pm .01$ & 0.81 \\
\hline $\begin{array}{c}\text { VC, } \\
\text { Baseline }\end{array}$ & 0 & 27 & 63 & 10 & 32.0 & $4.76 \pm .02$ & 0.73 \\
\hline $\begin{array}{l}\text { Reduced } \\
\text { EMC (a) }\end{array}$ & 0 & 37 & 63 & 0 & 32 & n.d. & n.d. \\
\hline $\begin{array}{l}\text { Reduced } \\
\text { EMC (b) }\end{array}$ & 0 & 54.5 & 45.5 & 0 & 36 & n.d. & n.d. \\
\hline 1 & 100 & 0 & 0 & 0 & n.d. & $148 \pm 2$ & 0.026 \\
\hline 2 & 80 & 6 & 14 & 0 & 49.0 & $42.3 \pm 0.7$ & \\
\hline 3 & 35 & 19.5 & 45.5 & 0 & n.d. & $6.50 \pm .04$ & 0.51 \\
\hline 4 & 10 & 27 & 63 & 0 & 31.0 & $4.60 \pm .01$ & .70 \\
\hline 5 & 31.5 & 17.6 & 40.9 & 10 & 35.0 & $7.53 \pm .05$ & 0.55 \\
\hline 6 & 9 & 24.3 & 56.7 & 10 & 32.5 & $4.54 \pm .05$ & 0.77 \\
\hline
\end{tabular}


Figure 2

A

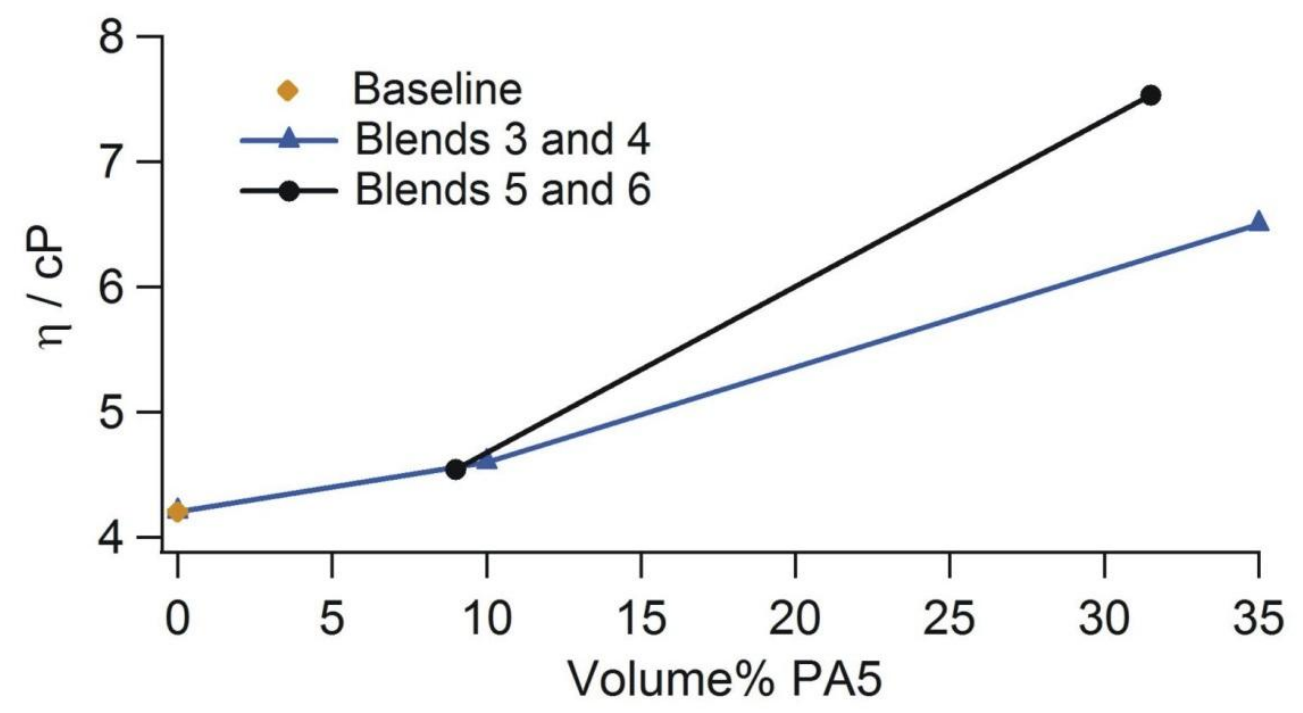

B

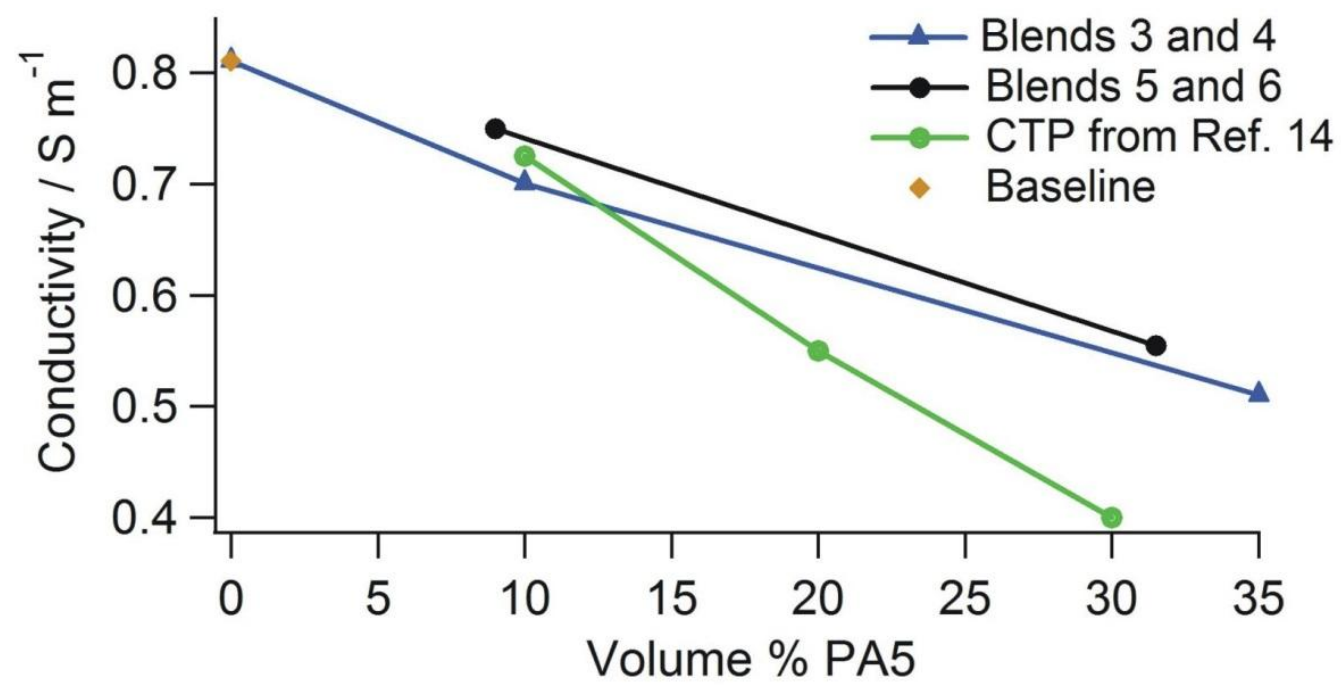


Figure 3:

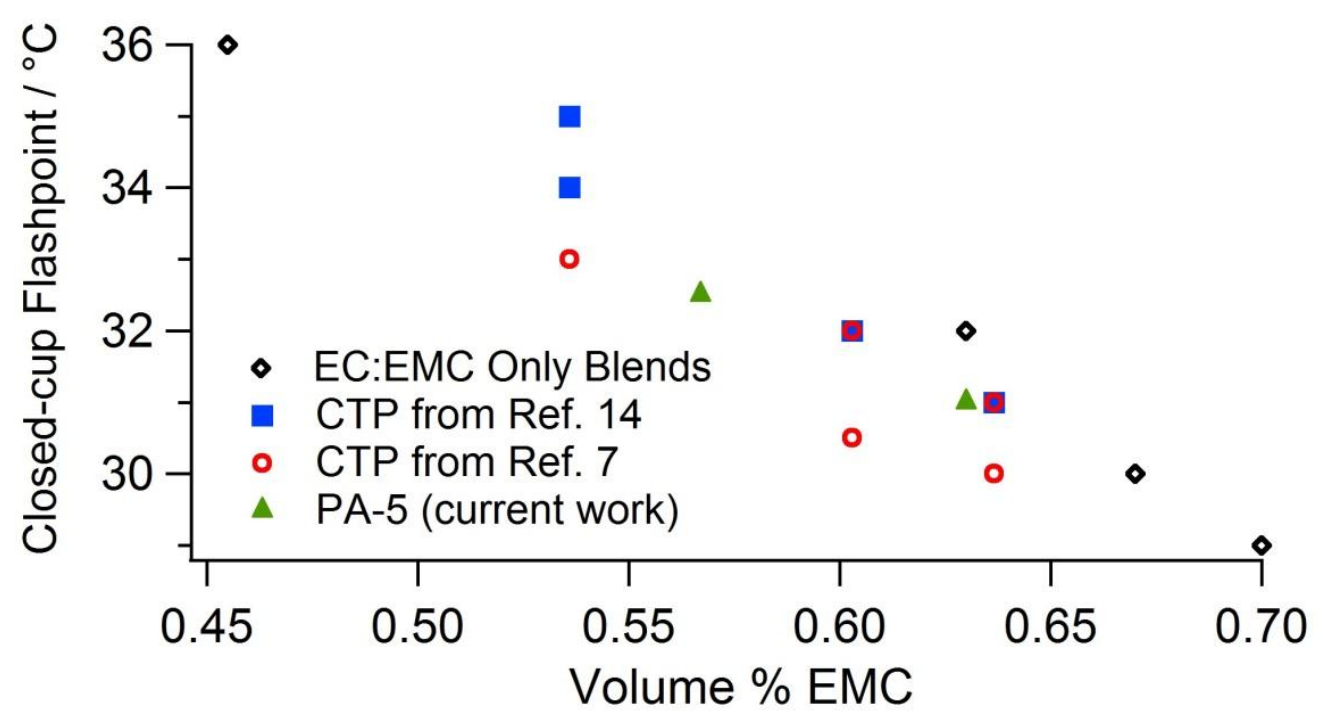


Figure 4:

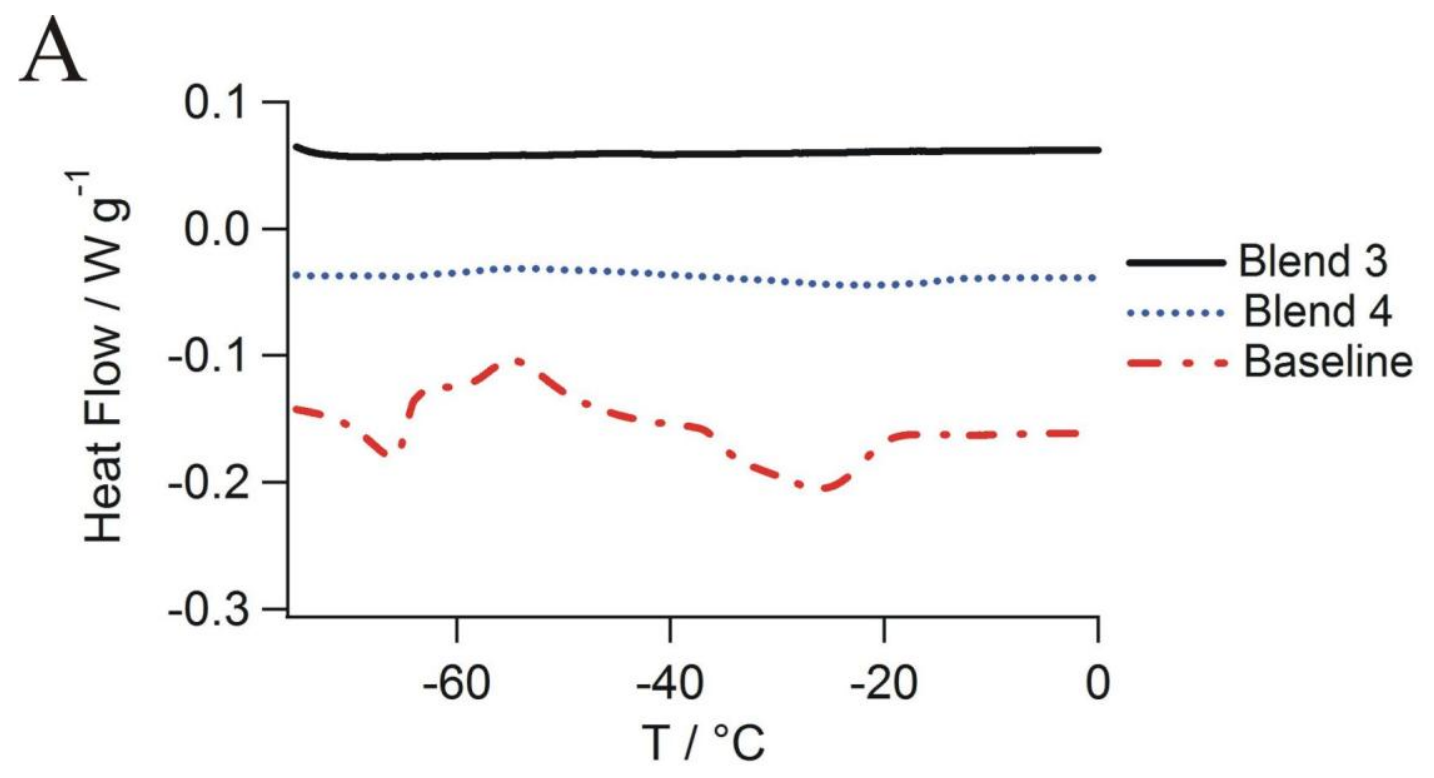

B

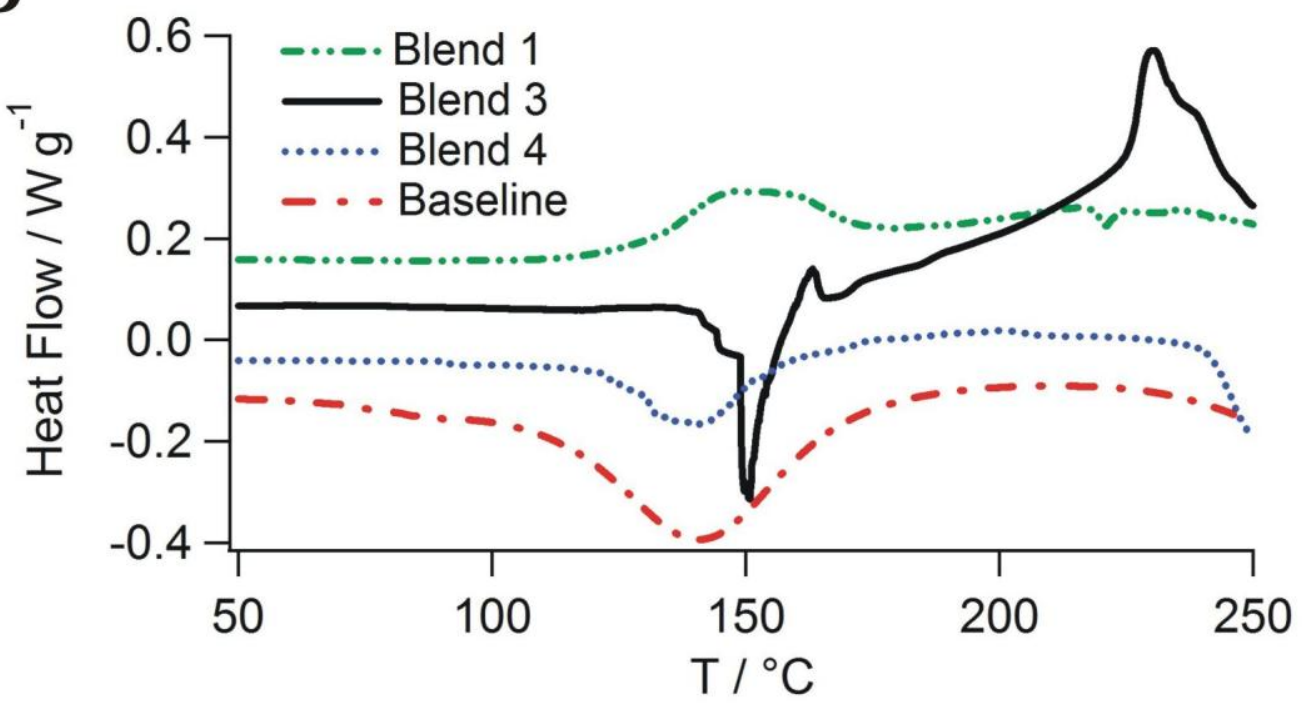


Figure 5:

A

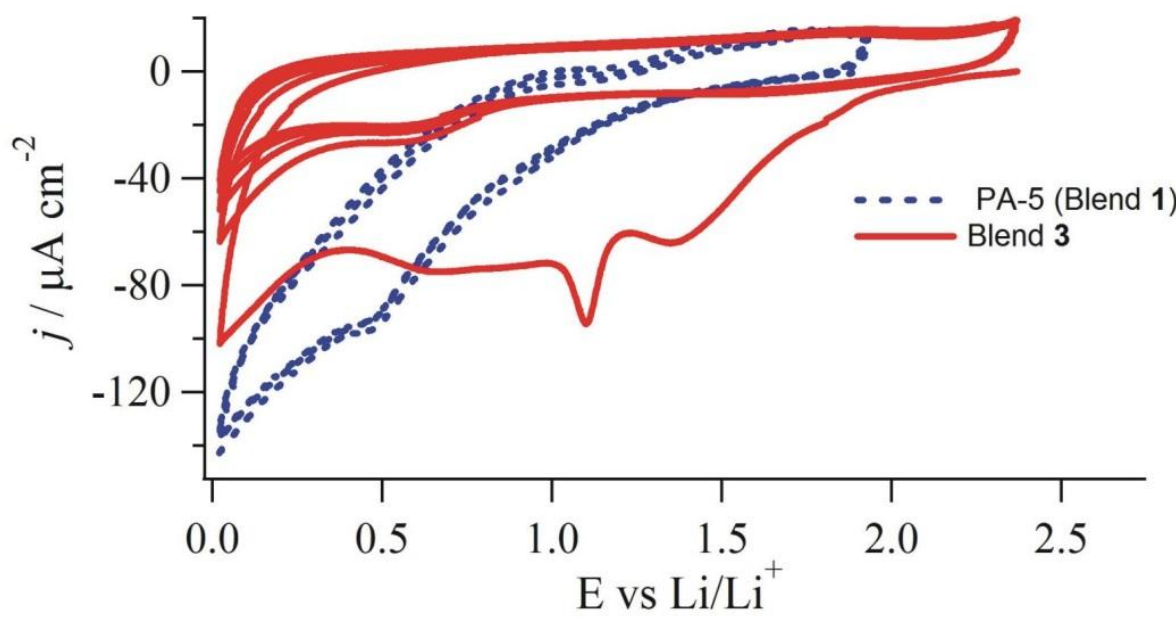

B
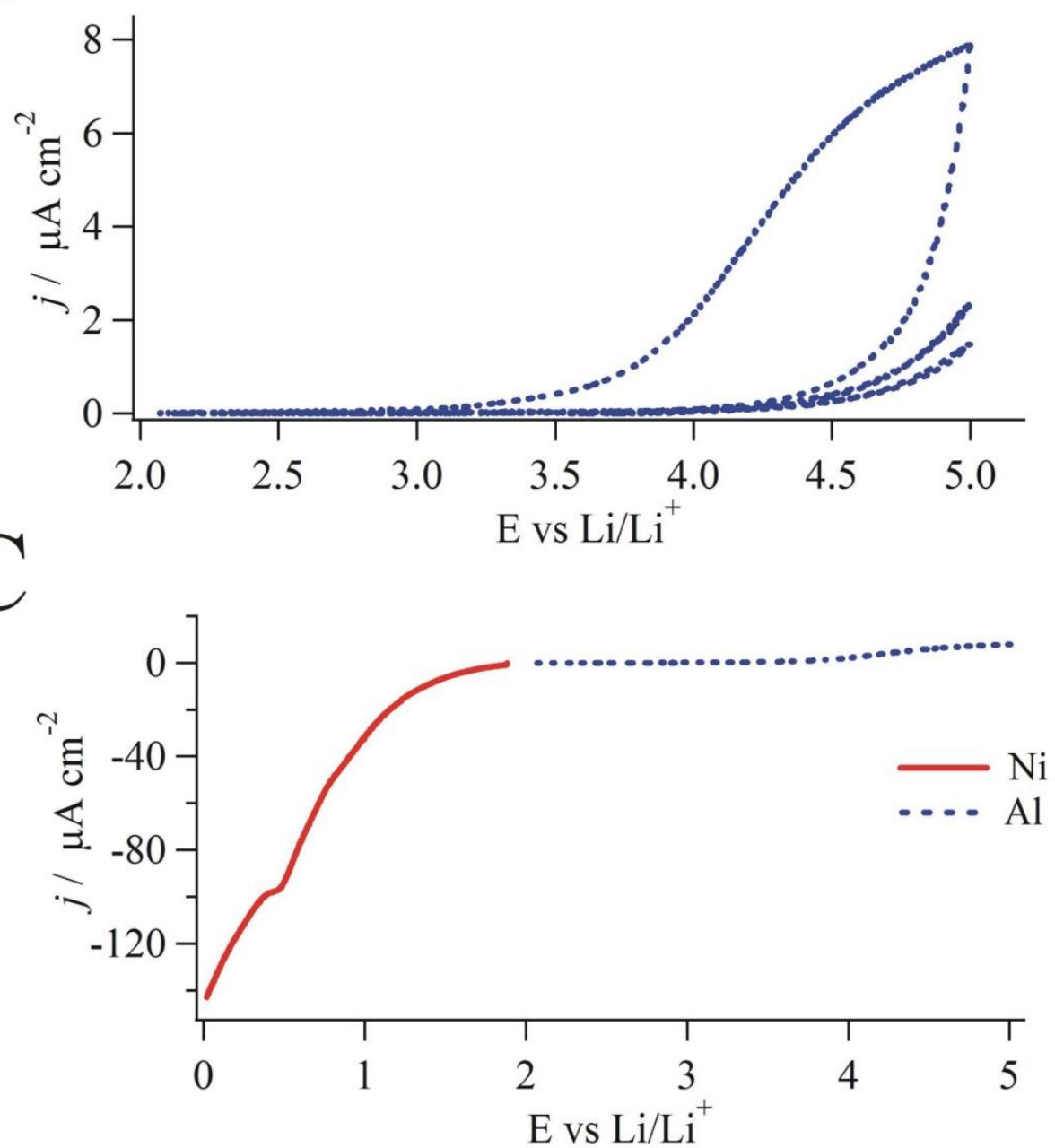
Figure 6:

A

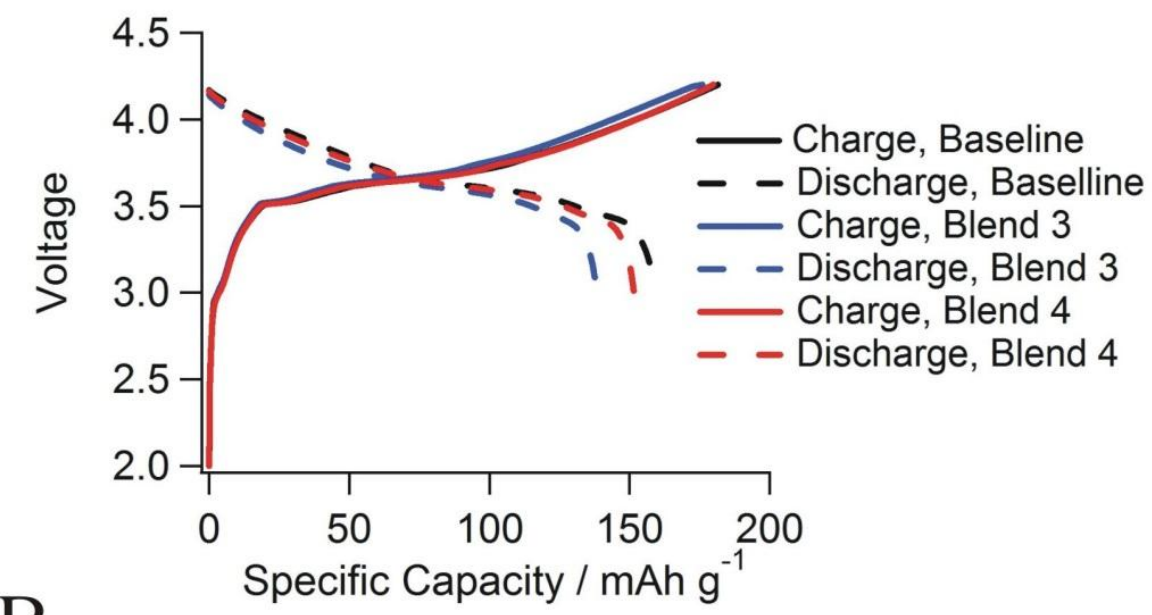

B

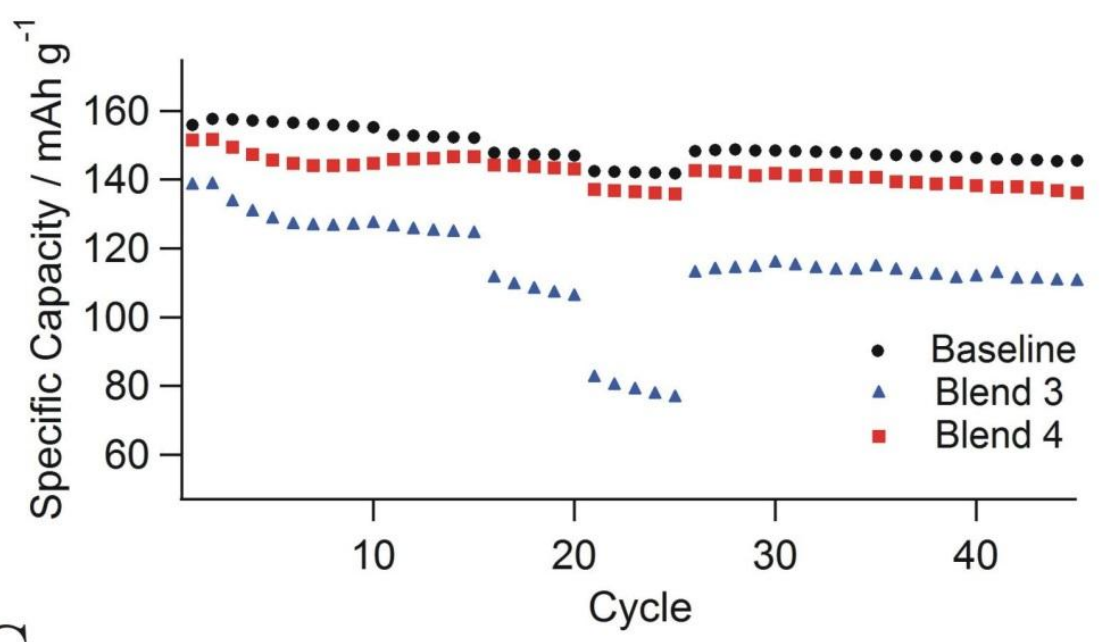

C

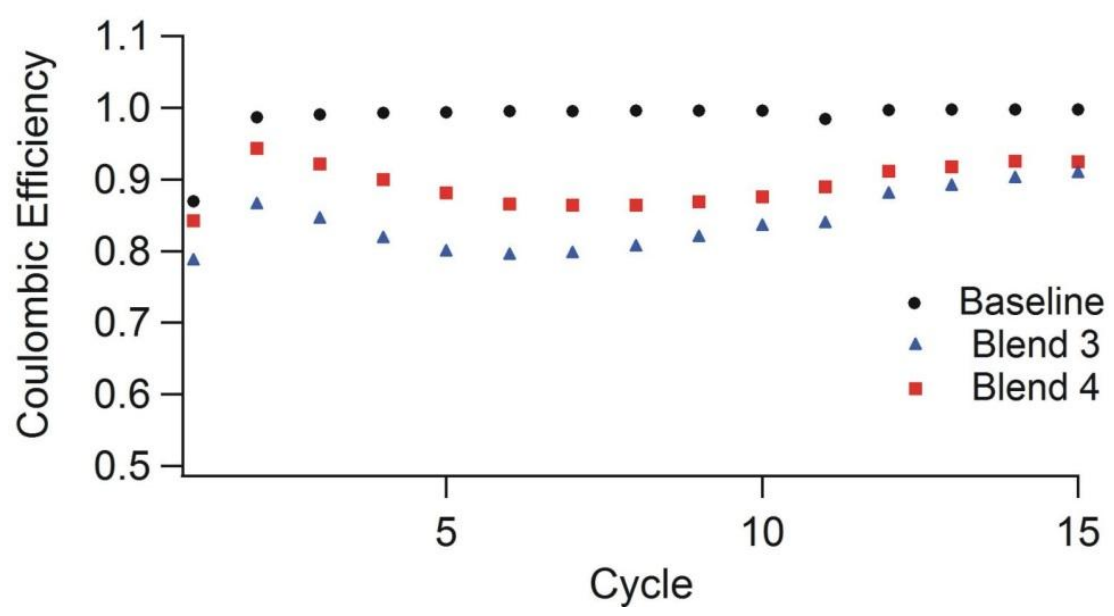


Figure 7:
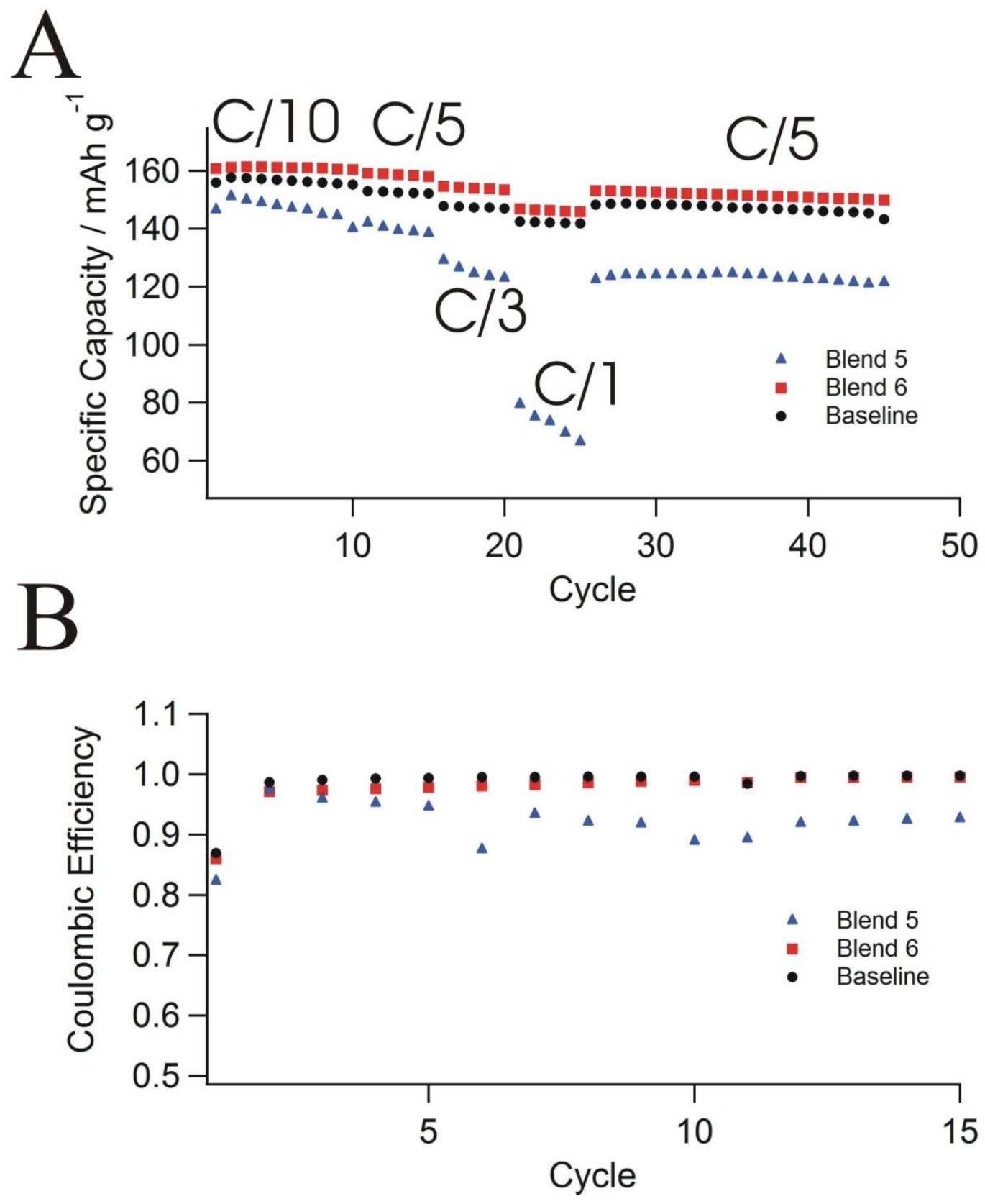
Figure 8:

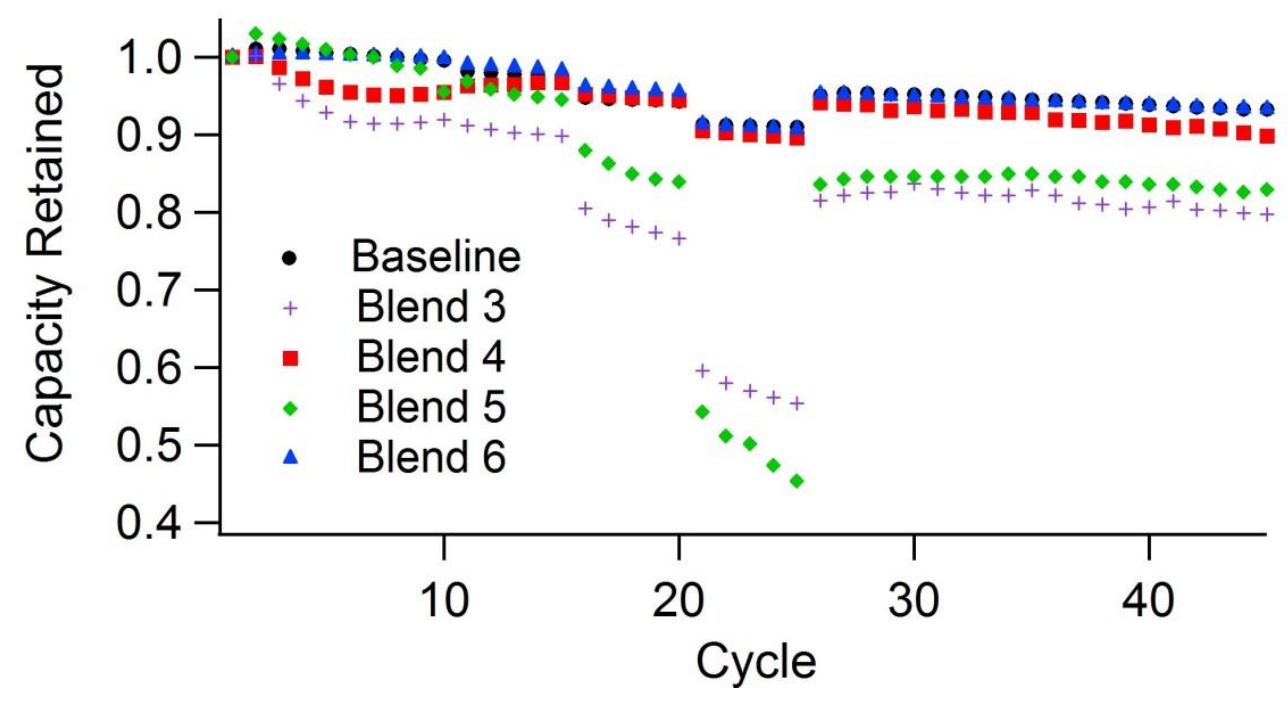


Figure 9:

A

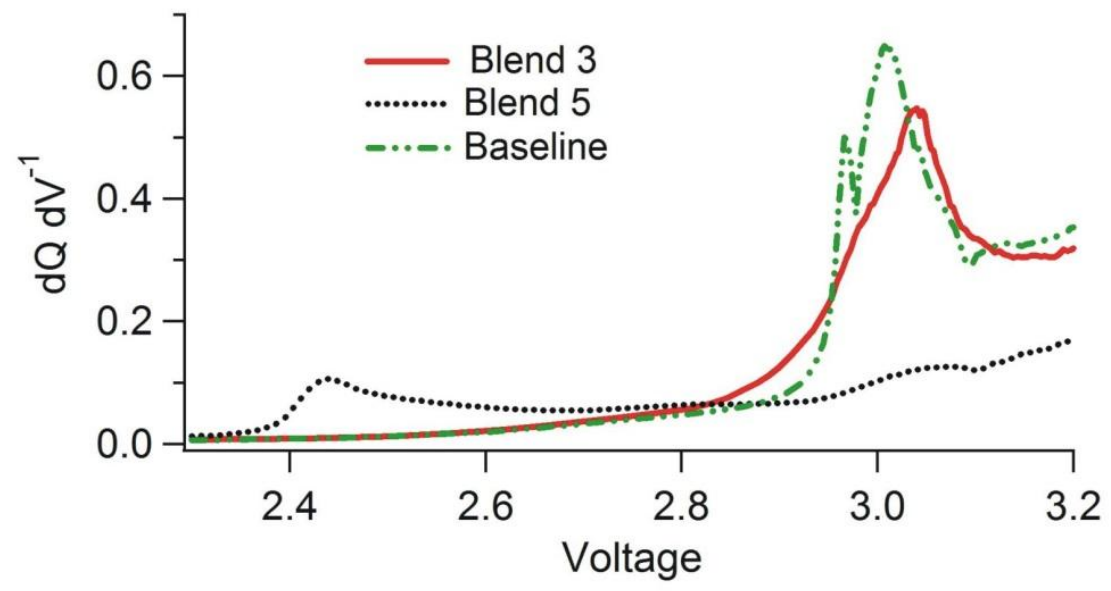

B
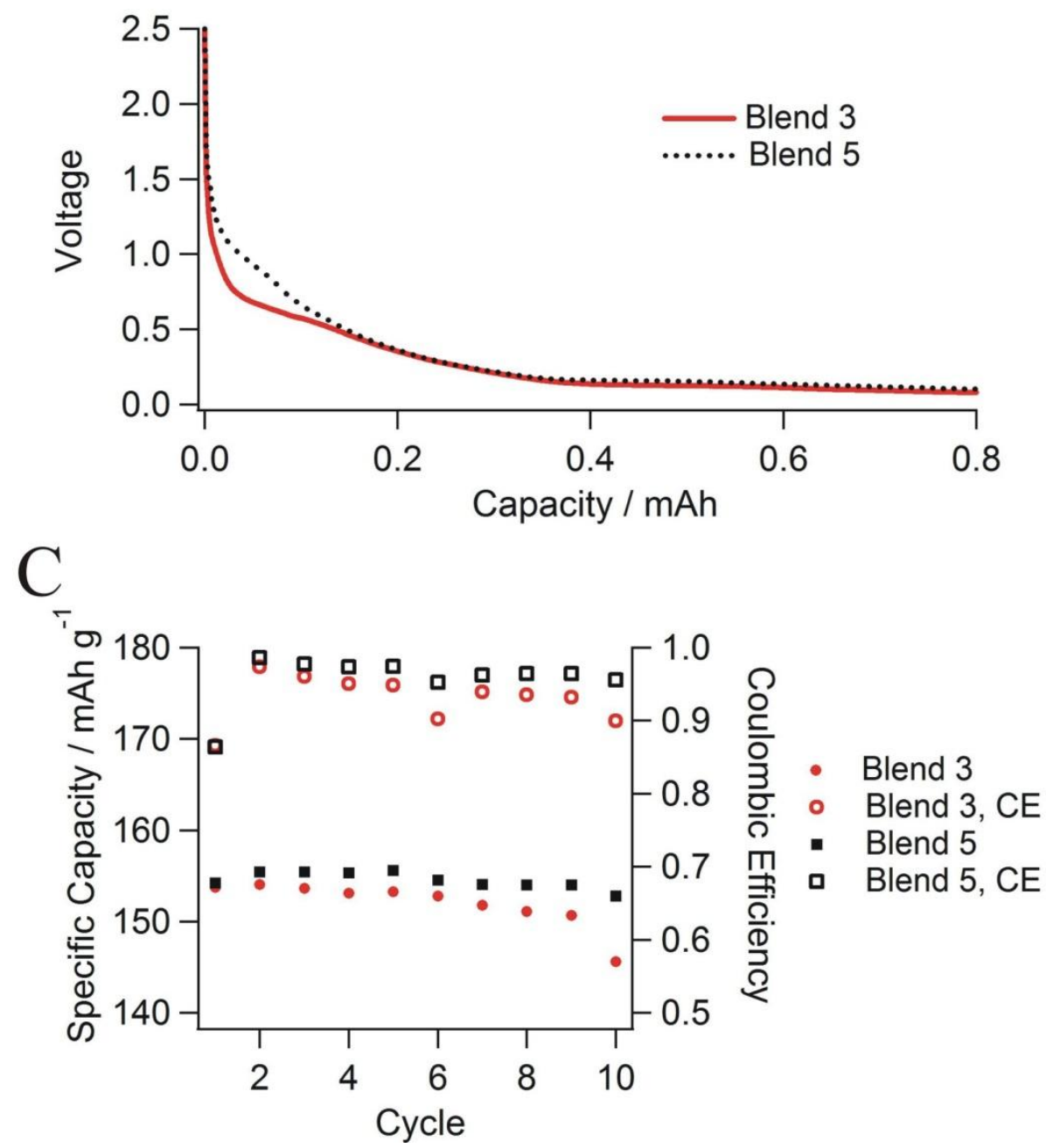